\title{
Seventeen-millimeter St. Jude Medical Regent valve in patients with small aortic annulus: dose moderate prosthesis-patient mismatch matter?
}

\author{
Jia Hu', Hong Qian', Ya-jiao Li², Jun Gu', Jing Janice Zhao' and Er-yong Zhang ${ }^{1 *}$
}

\begin{abstract}
Background: The study was designed to evaluate the effects of moderate prosthesis-patient mismatch (defined as $0.65 \mathrm{~cm}^{2} / \mathrm{m}^{2}$ indexed effective orifice area $\leq 0.85 \mathrm{~cm}^{2} / \mathrm{m}^{2}$ ) on midterm outcomes after isolated aortic valve replacement with a $17-\mathrm{mm}$ St. Jude Medical Regent valve in a large series of patients, and to determine if these effects are influenced by patient confounding variables.

Methods: One-hundred and six patients with and without moderate prosthesis-patient mismatch early after implantation of a 17-mm Regent valve at aortic position were included. Both clinical and echocardiographic assessments were performed preoperatively, at discharge and during follow-up period (mean follow-up time $52.6 \pm 11.9$ months).
\end{abstract}

Results: The prevalence of moderate prosthesis-patient mismatch was documented in 46 patients (43.4\%) at discharge. During the follow-up period, no difference in the regression of left ventricular mass, decrease of transvalvular pressure gradients, mortality and prosthesis-related complications was observed between patients with and without moderate prosthesis-patient mismatch. After adjustment for several risk factors, moderate prosthesis-patient mismatch was associated with increased midterm mortality in patients with baseline left ventricular ejection fraction $<50 \%$ (HR: 1.80, $p=0.02$ ), but with normal prognosis in those with preserved LV function. Younger age (cut off value $=65$ years) was not an independent predictor of increased midterm mortality and valve-related complications in patients with moderate prosthesis-patient mismatch.

Conclusions: Moderate prosthesis-patient mismatch after aortic valve replacement with a small mechanical prosthesis is associated with increased mortality and adverse events in patients with pre-existing left ventricular dysfunction. Selected patients with small aortic annulus can experience satisfactory clinical improvements and midterm survival after aortic valve replacement with a 17-mm Regent valve.

Keywords: Prosthesis-patient mismatch, 17-mm Regent valve, Aortic valve replacement, Clinical outcome

\section{Background}

Dealing with a small aortic root of less than $19 \mathrm{~mm}$ during aortic valve replacement (AVR) remains a challenging scenario for the cardiac surgeons with regard to operative techniques and selection of appropriate prosthesis [1-4]. As implantation of a smaller prosthetic valve without adequate effective orifice area index (EOAi) may predispose to unfavorable outcomes, several strategies at the time

\footnotetext{
*Correspondence: eyzhang@outlook.com

'Department of Cardiovascular Surgery, West China Hospital, Sichuan University, Chengdu, People's Republic of China

Full list of author information is available at the end of the article
}

of operation have been developed to avoid the feared prosthesis-patient mismatch (P-PtM, defined as EOAi $\leq$ $0.85 \mathrm{~cm}^{2} / \mathrm{m}^{2}$ ) [5-8], including the use of aortic root enlargement/replacement procedures with a larger prosthesis (eg. a stentless bioprosthesis or a new generation of stented bioprosthesis) or modern bileaflet mechanical valve implanted in the supra-annular position. However, these strategies are technically more difficult, require longer cardiopulmonary bypass times, and fail to point uniformly toward an improved clinical outcome $[2,3]$.

The 17-mm St. Jude Medical Regent (SJMR) valve with an improved hemodynamic profile is regarded as a valid 
option for patients who have small aortic roots $[9,10]$. Although the Regent valves offer a larger EOA than that of conventional prosthetic valves, the occurrence of P-PtM in patients with 17-mm SJMR valves is reported as high as $31 \%-94.1 \%$ [1,2,9-11]. The main hemodynamic consequence of P-PtM, especially the severe P-PtM $\left(\mathrm{EOAi} \leq 0.65 \mathrm{~cm}^{2} / \mathrm{m}^{2}\right)$, is to generate higher than expected transvalvular gradients, which is responsible for incomplete left ventricular mass (LVM) regression, increased valve-related complications and postoperative mortality [6,7,12-15]. However, controversies still exist as to the impacts of early postoperative moderate P-PtM $\left(0.65 \mathrm{~cm}^{2} / \mathrm{m}^{2}<\right.$ EOAi $\left.\leq 0.85 \mathrm{~cm}^{2} / \mathrm{m}^{2}\right)$ on late outcomes [5-7,12-15]. Moreover, reported experience with $17-\mathrm{mm}$ Regent valves in a large series of patients are rare. Thus, the objective of this study was to evaluate the effects of moderate P-PtM on midterm outcomes after isolated AVR with a 17-mm SJMR valve and to determine if these effects are modulated by patient's confounding variables.

\section{Methods \\ Patient profile}

From December 2006 and June 2012, consecutive 114 patients underwent isolated AVR with a $17-\mathrm{mm}$ SJMR valve in our hospital. Moderate P-PtM $\left(0.65 \mathrm{~cm}^{2} / \mathrm{m}^{2}<\right.$ EOAi $\left.\leq 0.85 \mathrm{~cm}^{2} / \mathrm{m}^{2}\right)$ was present in 106 patients and severe P-PtM (EOAi $<0.65 \mathrm{~cm}^{2} / \mathrm{m}^{2}$ ) in 8 patients. All the data were prospectively collected and retrospectively analyzed. One hundred and six patients were divided into two subsets according to the presence of moderate P-PtM at discharge. The study group comprised 79 women $(74.5 \%)$ and 27 men $(25.5 \%)$ with a mean age of $52.5 \pm 8.6$ years. Mean body surface area (BSA) was $1.56 \pm 0.16 \mathrm{~m}^{2}$. Fifty-four patients $(50.9 \%)$ were in New York Heart Functional (NYHA) class III/IV preoperatively. Our investigation, including follow-up studies, was approved by the Ethical Review Board of West China Hospital in compliance with the Declaration of Helsinki. All patients had previously granted permission for the anonymous use of their medical information. The demographic and clinical data of all patients are summarized in Table 1.

\section{Echocardiographic measurements and calculations}

Echocardiographic measurements included M-mode, twodimensional, continuous wave, and Doppler analysis. Standard M-mode cardiac dimensions were collected according to the criteria of the American Society of Echocardiography. All Doppler measurements were obtained as the average of at least 3 cycles in patients with sinus rhythm or more than 5 cycles in those with atrial fibrillation. The following parameters were collected: end-diastolic septal thickness, left ventricular end-diastolic dimension, and end-diastolic left ventricular posterior wall thickness. The peak and mean transvalvular gradients were calculated by the complete Bernoulli equation. The mass of the left ventricle (LV) was estimated according to the joint recommendations of the American and European associations of echocardiography using Devereux's [16] and indexed to BSA (LVMI). The effective orifice area (EOA) was determined by the standard continuity equation $\left.\left[\left(\mathrm{LVOT}^{2} \times 0.785 \times \mathrm{TVI}_{1}\right) / \mathrm{TVI}_{2}\right)\right]$, where $L V O T$ is the diameter of the left ventricular outflow tract, and $T V I_{1}$ and $T V I_{2}$ are the time-velocity integrals at the LVOT and across the aortic valve, respectively. The measured EOAi, a valid parameter for quantification of the severity of P-PtM, was calculated by dividing the EOA by the BSA. Also, the projected EOAi was derived from the published normal in vivo EOA values for the $17 \mathrm{~mm}$ SJMR valve and indexed to BSA [12]. Unless specified otherwise, EOAi throughout this article indicates measured EOAi.

\section{Operative techniques and anticoagulation therapy}

All patients were approached through a median sternotomy. Cardiopulmonary bypass was initiated after cannulation of the ascending aorta, superior vena cava and inferior vena cava. The operation was performed with moderate hypothermia and use of antegrade cold blood cardioplegia. No patient underwent aortic annulus enlargement or root replacement. After removal of the diseased leaflets and calcifications from the annulus, the size of the prosthesis was determined according to the diameter of the aortic annulus, which was measured with manufacturer's sizers (St. Jude Medical, USA). The 17-mm SJMR were then implanted in the supra-annular position using 2-0 interrupted polyester -non-everting mattress sutures in all patients. After the first postoperative day, patients received oral warfarin sodium at daily updated dosages according to the international normalized ratio of prothrombin time (PT-INR), with a target value maintained between 1.5 and 2.0.

\section{Follow-up}

Clinical follow-up was updated to June 2013 through direct hospital visits and structured telephone interviews for all survivors. Both clinical and echocardiographic assessments were scheduled by protocol at discharge (mean $7.4 \pm 2.1$ days), sixth postoperative month and yearly thereafter. Follow-up transthoracic echocardiographic data were obtained for 96 (93.2\%) of the 103 discharged patients at $45.8 \pm 8.8$ months after primary surgery. The clinical follow-up was $97.1 \%$ complete. Mean follow-up time was $52.6 \pm 11.9$ months (median, 50.5 months; range, 14-74 months). In case of new-onset symptoms, additional echo were performed, and the patient's follow-up charts were updated accordingly. The valve-related complications were defined according to the guidelines for reporting after cardiac valve interventions [17]. 
Table 1 Baseline clinical characteristics and operative data in patients with and without moderate prosthesis-patient mismatch (P-PtM)

\begin{tabular}{|c|c|c|c|c|}
\hline Variables & $\begin{array}{l}\text { Overall } \\
(n=106)\end{array}$ & $\begin{array}{l}\text { Non-PPM } \\
(n=58)\end{array}$ & $\begin{array}{l}\text { Moderate PPM } \\
(n=45)\end{array}$ & ${ }^{*} p$ value \\
\hline Age, years & $52.5 \pm 8.6$ & $52.1 \pm 10.2$ & $53.0 \pm 12.7$ & 0.398 \\
\hline \multicolumn{5}{|l|}{ Age group, years } \\
\hline$\leq 65$ & $56(52.8 \%)$ & $30(51.7 \%)$ & $25(55.6 \%)$ & 0.831 \\
\hline$>65$ & $50(47.2 \%)$ & $28(48.3 \%)$ & $20(44.4 \%)$ & 0.815 \\
\hline Female sex & $79(74.5 \%)$ & $53(91.4 \%)$ & $23(51.1 \%)$ & 0.047 \\
\hline Height (m) & $1.65 \pm 0.09$ & $1.62 \pm 0.05$ & $1.69 \pm 0.04$ & 0.106 \\
\hline Body surface area $\left(\mathrm{m}^{2}\right)$ & $1.56 \pm 0.16$ & $1.48 \pm 0.09$ & $1.66 \pm 0.16$ & 0.038 \\
\hline Projected EOAI $\left(\mathrm{cm}^{2} / \mathrm{m}^{2}\right)$ & $0.90 \pm 0.04$ & $0.95 \pm 0.03$ & $0.84 \pm 0.02$ & 0.041 \\
\hline Body mass index $\left(\mathrm{kg} / \mathrm{m}^{2}\right)$ & $22.9 \pm 2.8$ & $22.1 \pm 1.1$ & $22.9 \pm 2.7$ & 0.109 \\
\hline \multicolumn{5}{|l|}{ Pre-NYHA class } \\
\hline$|/| \mid$ & $52(49.1 \%)$ & $35(60.3 \%)$ & $16(35.6 \%)$ & 0.097 \\
\hline III/IV & $54(50.9 \%)$ & 23(39.7\%) & $29(64.4 \%)$ & 0.105 \\
\hline \multicolumn{5}{|l|}{ Ejection fraction } \\
\hline$\geq 50 \%$ & $45(44.3 \%)$ & $30(51.7 \%)$ & 15(33.3\%) & 0.159 \\
\hline$<50 \%$ & $58(55.7 \%)$ & $28(48.3 \%)$ & $30(66.7 \%)$ & 0.207 \\
\hline Atrial fibrillation & $15(14.2 \%)$ & $9(15.5 \%)$ & $4(8.9 \%)$ & 0.281 \\
\hline Chronic heart failure & $13(12.3 \%)$ & $5(8.6 \%)$ & $8(17.8 \%)$ & 0.178 \\
\hline Ischemic heart disease & $37(19.8 \%)$ & $21(36.2 \%)$ & 13(28.9\%) & 0.362 \\
\hline Renal insufficiency & $8(7.5 \%)$ & $5(8.6 \%)$ & $3(6.7 \%)$ & 0.518 \\
\hline Hypertension & $36(34.0 \%)$ & $21(36.2 \%)$ & 15(33.3\%) & 0.496 \\
\hline Diabetes & $29(27.3 \%)$ & $10(17.2 \%)$ & $16(35.6 \%)$ & 0.079 \\
\hline \multicolumn{5}{|l|}{ Valve pathology } \\
\hline Degenerative & $33(31.1 \%)$ & $18(31.0 \%)$ & 14(31.1\%) & 0.557 \\
\hline Rheumatic & $53(50.0 \%)$ & $27(46.6 \%)$ & $25(55.6 \%)$ & 0.364 \\
\hline Infective & $3(2.8 \%)$ & $2(3.4 \%)$ & $1(2.2 \%)$ & 0.599 \\
\hline CPB time (min) & $108 \pm 32$ & $105 \pm 21$ & $110 \pm 35$ & 0.541 \\
\hline Cross-clamp time (min) & $90 \pm 23$ & $87 \pm 18$ & $92 \pm 27$ & 0.617 \\
\hline In-hospital death & $3(2.8 \%)$ & - & - & - \\
\hline
\end{tabular}

NYHA, New York Heart Association; CPB, cardiopulmonary bypass; EOAl, effective orifice area index; *Data were compared between the non-PPM group and the moderate PPM group.

\section{Statistical analysis}

Continuous variables are presented as mean \pm standard deviation and categorical data as percentages unless otherwise specified. Differences in pre- and postoperative echocardiographic data for all patients were compared and analyzed by paired Student's t-test. Differences in patients with and without moderate P-PtM early after surgery were analyzed by $\chi^{2}$, Fisher exact or unpaired Student's $t$ test as appropriate. Pearson's coefficient was used to analyze the correlation between the projected EOAi and the measured EOAi. The actuarial survival rate and ratio of patients without valve-related complications were calculated by the Kaplan-Meier method and compared between groups by using a log-rank test. Cox proportional-hazards regression model was used to determine whether the occurrence of moderate PPtM was associated with increased risk of valve-related complications and intermediate-term mortality. Variables with a univariate $p<0.2$ or those of known clinical importance for survival and adverse events were submitted to the multivariate models to calculate hazards ratios (HR) and its 95\% confidence intervals $(\mathrm{CI})$. All $p$ values less than 0.05 were considered statistically significant. All statistical analyses were performed using Statistical Package for Social Sciences version 16.0 (SPSS Inc, Chicago, IL, USA). 


\section{Results}

\section{Operative morbidity and mortality}

In-hospital mortality was $2.8 \%$ (3 patients). The causes of the in-hospital death were cerebral infarction (1 patient), respiratory failure (1 patient) and low cardiac output syndrome (1 patient). The early postoperative period was complicated in two patients by atrioventricular block requiring pacemaker implantation. Univariate analysis identified left ventricular ejection fraction (LVEF) $<35 \%$ as an independent predictor of in-hospital mortality (HR 1.32, $95 \%$ CI: 1.09 to $1.78, \mathrm{p}=0.041$ ). However, multivariable analysis yielded no significant predictor of early postoperative death. Two patients experienced perioperative intra-aortic balloon pumping for hemodynamic instability.

\section{Clinical follow-up and valve-related complications}

During follow-up, NYHA functional class improved in the entire cohort and the improvement was not significantly different between the groups with and without moderate P-PtM. Three patients were readmitted due to prosthetic endocarditis, two patients were reoperated for paravalvular leakage, and one patient experienced cerebral hemorrhage. Late cerebral infarction, prosthetic thrombosis, and structural failure of the mechanical valves did not occur in any patient during follow-up. Freedom from valve-related complications at 1-year, 3-year, and 5-year was 97.2\%, $94.3 \%$, and $89.9 \%$, respectively (Figure 1A). Univariate analysis identified atrial fibrillation, diabetes and renal insufficiency were associated with an increased risk of postoperative valve-related complications, and only diabetes was identified as the independent predictor of valve-related complications by multivariate analysis (Table 2). Freedom from reoperation at an average of $52.6 \pm 11.9$ months after primary AVR was $98.0 \%$. Long-term survival and freedom from cardiovascular death are shown in Figure 1B. Of the 103 survivors, 12 patients $(10.6 \%)$ died during the follow-up period: myocardium infarction $(n=2)$, malignancy $(n=2)$, heart failure $(n=2)$, sepsis $(n=2)$, pneumonia $(\mathrm{n}=1)$, renal failure $(\mathrm{n}=1)$, unknown $(\mathrm{n}=2)$. Actuarial 1-year, 3-year, and 5-year survival rate were $96.2 \%, 89.4 \%$, and $80.5 \%$, respectively. Univariate analysis revealed age, preoperative LVEF $<35 \%$, diabetes, renal insufficiency, and a concomitant coronary surgery as predictors of overall mortality (including in-hospital death). Multivariate analysis showed diabetes and preoperative LVEF $<35 \%$ to be the independent predictors of the postoperative death (Figure 2). Freedom from cardiovascular death at 1 -year, 3-year, and 5-year was $98.1 \%, 95.9 \%$, and $90.2 \%$, respectively. As for the 8 patients with severe P-PtM at discharge, only one anticoagulation-related complication was observed and no cardiovascular death was observed during an average of $48.7 \pm 8.9$ months follow-up.

\section{Echocardiographic follow-up}

The baseline and postoperative echocardiographic data of all patients are reported in Table 3. A significant reduction in peak and mean transvalvular gradient was observed in all patients, with a mean difference versus preoperative values of $82.9 \pm 29.5 \mathrm{mmHg}$ and $50.2 \pm 16.8 \mathrm{mmHg}$, respectively. Follow-up echocardiography also revealed a significant regression of LVMI, decreasing from preoperative values of $196.1 \pm 44.3 \mathrm{~g} / \mathrm{m}^{2}$ to $118.9 \pm 30.8 \mathrm{~g} / \mathrm{m}^{2}$ after surgery. During follow-up, the mean EOA and EOAi were significantly increased compared with preoperative values. No significant difference between preoperative and postoperative LVEF was observed.

\section{Relationship between the projected EOAi and measured EOAi}

The projected EOAi of the two groups was calculated and significant difference between groups was observed (Table 1). A significant correlation between the projected EOAi and measured EOAi was observed $(r=0.74, p=$ $0.03)$. However, in the subgroup analysis of patients with LVEF $<50 \%(n=58)$, the projected EOAi moderately correlated with the measured EOAi $(\mathrm{r}=0.59, \mathrm{p}=0.051)$, and the projected EOAi has a sensitivity of $74 \%$ and specificity of $55 \%$ for predicting moderate P-PtM postoperatively.

Effects of P-PtM on clinical and echocardiographic variables The prevalence of moderate P-PtM, defined as an EOAI ranging from $0.65 \mathrm{~cm}^{2} / \mathrm{m}^{2}$ to $0.85 \mathrm{~cm}^{2} / \mathrm{m}^{2}$, was
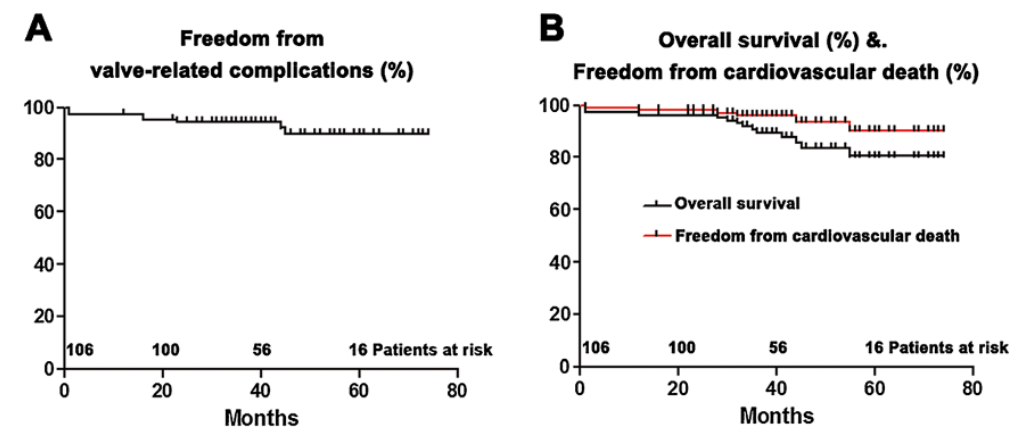

Figure 1 (A) Freedom from valve-related complications; (B) Midterm survival and freedom from cardiac death. 
Table 2 Univariate and multivariate analysis for independent predictors of valve-related complications and mortality

\begin{tabular}{|c|c|c|c|c|}
\hline \multirow[t]{3}{*}{ Variables } & \multicolumn{2}{|c|}{ Valve-related complications } & \multicolumn{2}{|c|}{ Overall mortality } \\
\hline & Univariate & Multivariate & Univariate & Multivariate \\
\hline & (P value) & HR[95\% Cl], P value & (P value) & $\mathrm{HR}[95 \% \mathrm{Cl}], \mathrm{P}$ value \\
\hline$<65$ years & 0.165 & $3.4[0.6-8.1], 0.320$ & 0.108 & $1.6[0.8-2.7], 0.245$ \\
\hline$\geq 65$ years & 0.087 & $0.9[0.2-1.6], 0.194$ & 0.047 & $1.3[1.0-1.7], 0.071$ \\
\hline Sex: male & 0.548 & - & 0.876 & - \\
\hline Body mass index & 0.265 & - & 0.178 & - \\
\hline |//1 & 0.374 & - & 0.217 & - \\
\hline III/IV & 0.081 & $1.5[0.9-2.8], 0.075$ & 0.098 & $1.4[1.0-1.6], 0.059$ \\
\hline$>50 \%$ & 0.727 & - & 0.324 & - \\
\hline $35 \%-50 \%$ & 0.165 & $2.0[1.1-3.7], 0.234$ & 0.061 & $1.3[0.9-1.7], 0.088$ \\
\hline$<35 \%$ & 0.071 & $1.3[0.7-1.9], 0.128$ & $<0.001$ & $2.0[1.1-3.7], 0.021$ \\
\hline$>0.85 \mathrm{~cm}^{2} / \mathrm{m}^{2}$ & 0.791 & - & 0.564 & - \\
\hline$>0.65$ to $<0.85 \mathrm{~cm}^{2} / \mathrm{m}^{2}$ & 0.108 & $1.2[0.9-1.4], 0.144$ & 0.145 & $1.2[0.9-1.6], 0.188$ \\
\hline Atrial fibrillation & 0.013 & $1.1[0.5-2.7], 0.088$ & 0.076 & $1.3[0.2-2.2], 0.064$ \\
\hline Congestive heart failure & 0.102 & $1.6[0.7-2.9], 0.268$ & 0.128 & $2.2[0.6-2.1], 0.091$ \\
\hline Renal insufficiency & 0.041 & 2.3[0.8-4.3], 0.099 & 0.027 & $1.6[0.3-3.3], 0.054$ \\
\hline Hypertension & 0.323 & - & 0.279 & - \\
\hline Diabetes mellitus & $<0.001$ & $3.2[1.8-6.4], 0.015$ & $<0.001$ & $3.8[2.0-5.9], 0.002$ \\
\hline Chronic lung disease & 0.094 & $1.7[0.6-3.3], 0.102$ & 0.211 & $1.6[0.1-1.8], 0.069$ \\
\hline Concomitant CABG & 0.072 & $1.6[0.8-4.1], 0.109$ & 0.033 & $3.1[0.9-8.7], 0.084$ \\
\hline CPB time (min) & 0.382 & $1.0[0.8-1.2], 0.502$ & 0.089 & $1.6[0.8-2.3], 0.069$ \\
\hline Cross-clamp time (min) & 0.687 & $1.0[0.3-3.5], 0.751$ & 0.139 & $1.5[1.1-2.1], 0.078$ \\
\hline
\end{tabular}

CABG, coronary artery bypass grafting; $\mathrm{Cl}$, confidence intervals; HR, hazard ratio; other abbreviations as in Tables 1.

documented in 46 patients at discharge (43.4\%). In comparison to the patients without P-PtM, the group of patients with moderate P-PtM had a significantly greater mean BSA, proportion of males and bicuspid aortic valve disease (Table 1). As demonstrated in Table 3, the EOAI at discharge were significantly lower in patients with moderate P-PtM than in those without P-PtM. During the follow-up period, no difference in the regression of LVMI, decrease of transvalvular pressure gradients, valve-related complications and overall survival (Figure 2A and Figure 2B) between groups was observed. However, moderate P-PtM was associated with increased midterm mortality in patients with LV ejection fraction $<50 \%$ (HR 1.80, 95\% CI: 1.32 to $2.46, \mathrm{p}=0.02$ ), but not in patients with preserved LV systolic function (Figure $2 \mathrm{C}$ and Figure 2D). Young age $(<65$ years) was not associated with an increased risk of midterm mortality in patients with moderate P-PtM at discharge (Figure 2E and Figure 2F).

\section{Discussion}

The present study demonstrated satisfactory outcomes of AVR with 17-mm SJMR valve in terms of midterm survival, physical capacity and hemodynamic performances. The data of our study corroborate with previous studies indicating the presence of moderate P-PtM early after surgery was not a risk factor of intermediate mortality. However, in our subgroup analysis, moderate P-PtM was associated with a significant decrease in overall survival in patients with impaired LV systolic function. These findings emphasize the importance of a prospective strategy for selection of appropriate AVR candidate and operative methods to achieve satisfactory results in patients with small aortic annulus.

Although the 17-mm SJMR valve is a new generation of aortic prosthesis with an improved hemodynamic profile, the beneficial effects of implanting this mechanical valve in patients with small aortic roots remain unclear, particularly in young patients and in the mid- to long-term. Okamura group reported a cohort of elderly patients (mean age $>70$ years) demonstrating satisfactory clinical improvement and regression of LVM after AVR with the 17-mm SJMR $[2,10,11]$. Similarly, a series of studies demonstrated favorable clinical outcomes, as well as improved hemodynamic performance both at rest and under an exercise load [2,8-11,18,19], after AVR with a 17-mm SJMR valve. However, these studies are mostly presented with a small number of elderly patients during a relatively short follow-up period. As the moderate P-PtM frequently 


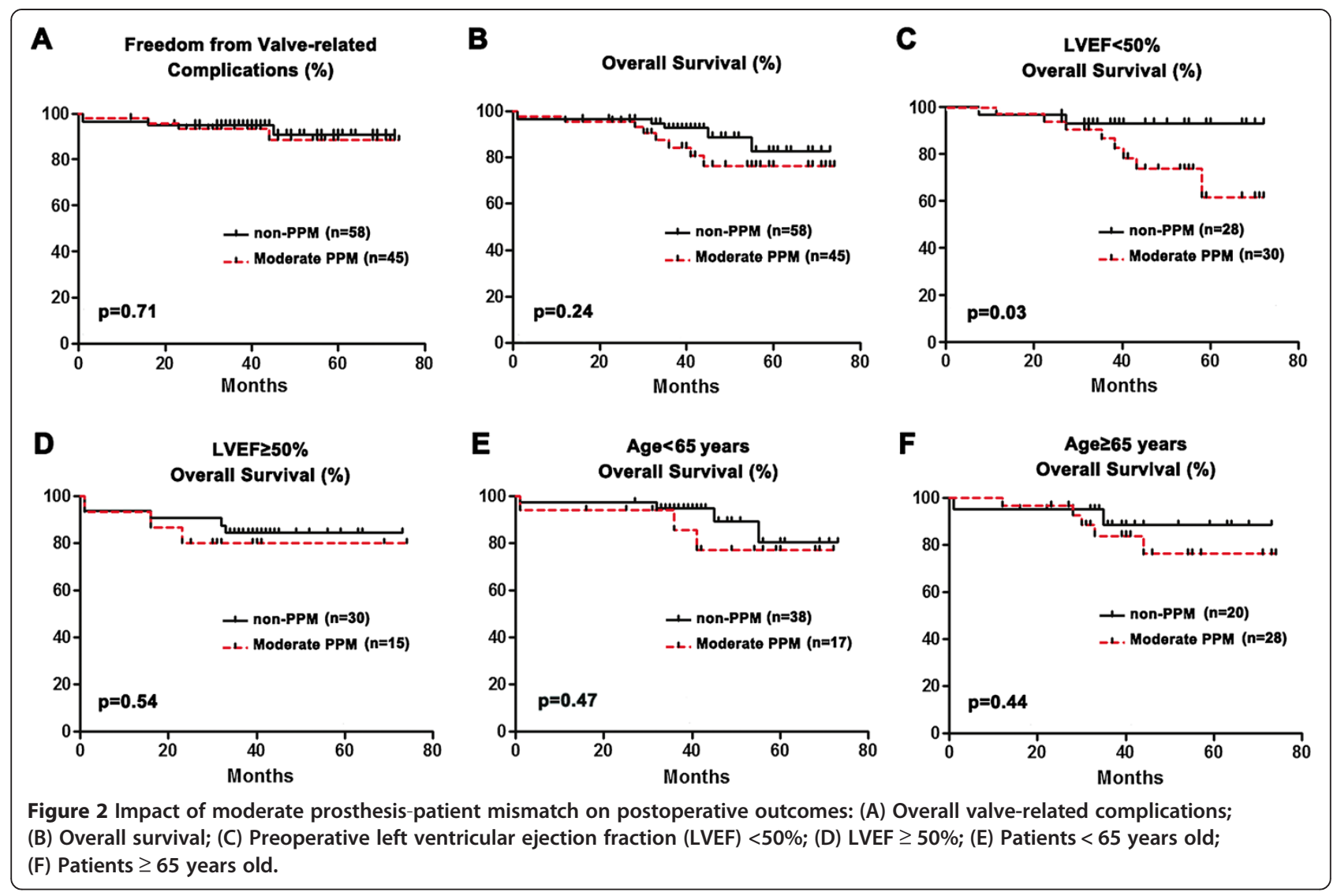

occurred after implantation of a small aortic Regent valve [1,2,9-11], its potential adverse effects on postoperative outcomes are not well characterized. Therefore, we need to investigate furtherly into the safety and effectiveness of the 17-mm SJMR in a large number of patients of all ages.

Apart from its improved hemodynamic performances, the $17-\mathrm{mm}$ SJMR valve was applied in this population for several other reasons. First, our patients presented with a relatively high-risk characteristics [high proportion of female patients (74.5\%), NYHA class III/IV (50.9\%), LVEF $<50 \%$ (55.7\%), and concomitant coronary surgery (34.9\%)], and therefore a "quick and simple" procedure was required to reduce myocardial ischemic time. It is clinically evident that a prolonged aortic cross-clamp time is one of the most important risk factors for post-AVR adverse events $[3,4,6,7]$. Although aortic root enlargement procedures or stentless prosthesis implantation are feasible options for patients with small aortic annulus, these procedures are technically more difficult and time consuming, and may result in higher morbidity than simple valve replacement, particularly in our patients who often have a severe calcified aortic root due to rheumatic and degenerative etiologies (81.1\%). Moreover, a series of studies have clearly indicated that a better hemodynamic outcome early after surgery in patients underwent aortic root enlargement and AVR could not translate into an improved postoperative survival compared with patients with isolated AVR [2-4].

An important finding of this study is that moderate PPtM is associated with increased postoperative mortality in patients with LVEF $<50 \%$, but with normal prognosis in those with preserved ventricular function. Since patients with impaired LV function are more vulnerable to the excessive afterload imposed by P-PtM, it is reasonable to find in our series that the follow-up mortality are significantly increased in patients with a combination of moderate P-PtM and impaired LV systolic function. Studies from several groups also clearly indicated that the influential role of moderate P-PtM on late survival is more important in patients with reduced ventricular reserve than in those with preserved LV function $[12,13]$. On the contrary, however, some others failed to identify the moderate P-PtM as an independent predictor of valverelated complication and mortality after AVR $[15,19]$. These compelling evidence may be partially explained by the fact that investigators used different parameters (eg. projected, geometric or in vivo measured EOAi) to identify P-PtM and quantify its severity. As demonstrated in the present study, using the projected EOAi in predicting P-PtM in patients with $\mathrm{LVEF}<50 \%$ has a lower accuracy; therefore, the projected EOAi to determine prediction and outcomes of P-PtM is of 
Table 3 Echocardiographic preoperative and post-operative data

\begin{tabular}{|c|c|c|c|c|}
\hline Variables & $\begin{array}{l}\text { Overall } \\
(n=103)\end{array}$ & $\begin{array}{l}\text { Non-PPM } \\
(n=58)\end{array}$ & $\begin{array}{l}\text { Moderate PPM } \\
(n=45)\end{array}$ & $p$ value $^{*}$ \\
\hline \multicolumn{5}{|l|}{ Preoperative data } \\
\hline Peak TVG (mmHg) & $115.2 \pm 38.7$ & $121.4 \pm 36.9$ & $107.2 \pm 31.8$ & 0.362 \\
\hline Mean TVG (mmHg) & $68.1 \pm 21.9$ & $71.2 \pm 18.79$ & $64.1 \pm 26.8$ & 0.381 \\
\hline LVMI $\left(\mathrm{g} / \mathrm{m}^{2}\right)$ & $196.1 \pm 44.3$ & $201.7 \pm 54.6$ & $188.8 \pm 68.4$ & 0.154 \\
\hline EOAI $\left(\mathrm{cm}^{2} / \mathrm{m}^{2}\right)$ & $0.44 \pm 0.18$ & $0.42 \pm 0.16$ & $0.47 \pm 0.08$ & 0.631 \\
\hline Ejection fraction (\%) & $58.4 \pm 11.9$ & $59.8 \pm 12.6$ & $56.6 \pm 9.9$ & 0.184 \\
\hline \multicolumn{5}{|c|}{ Postoperative (at discharge) data } \\
\hline Peak TVG (mmHg) & $\mathrm{a} 31.8 \pm 12.1$ & ${ }^{\mathrm{a}} 28.7 \pm 13.4$ & $\mathrm{a} 35.8 \pm 16.1$ & 0.398 \\
\hline Mean TVG (mmHg) & ${ }^{\mathrm{a}} 17.2 \pm 5.98$ & ${ }^{\mathrm{a}} 16.3 \pm 4.69$ & ${ }^{\mathrm{a}} 18.4 \pm 7.9$ & 0.691 \\
\hline LVMI $\left(g / m^{2}\right)$ & $170.8 \pm 48.9$ & $167.1 \pm 39.1$ & $175.6 \pm 54.3$ & 0.437 \\
\hline EOAI $\left(\mathrm{cm}^{2} / \mathrm{m}^{2}\right)$ & ${ }^{\mathrm{a}} 0.91 \pm 0.21$ & $\mathrm{a}_{1.01 \pm 0.13}$ & ${ }^{\mathrm{a}} 0.78 \pm 0.09$ & $<0.01$ \\
\hline Ejection fraction (\%) & $56.9 \pm 15.4$ & $58.1 \pm 13.4$ & $55.3 \pm 10.9$ & 0.697 \\
\hline \multicolumn{5}{|l|}{ Follow-up data } \\
\hline Peak TVG (mmHg) & $b_{32.3 \pm 8.91}$ & ${ }^{b} 29.6 \pm 7.4$ & $b_{35.1 \pm 11.4}$ & 0.412 \\
\hline Mean TVG (mmHg) & $b_{17.9} \pm 6.79$ & $\mathrm{~b}_{16.8} \pm 5.14$ & $\mathrm{~b}_{19.3} \pm 8.16$ & 0.689 \\
\hline LVMI $\left(g / m^{2}\right)$ & $\mathrm{b}_{118.9 \pm 30.8}$ & $\mathrm{~b}_{117.1 \pm 26.1}$ & $b_{121.2 \pm 33.8}$ & 0.186 \\
\hline EOAI $\left(\mathrm{cm}^{2} / \mathrm{m}^{2}\right)$ & ${ }^{b} 0.96 \pm 0.18$ & ${ }^{b} 0.99 \pm 0.21$ & ${ }^{b} 0.92 \pm 0.16$ & 0.781 \\
\hline Ejection fraction (\%) & $60.1 \pm 6.5$ & $61.2 \pm 7.1$ & $58.7 \pm 10.3$ & 0.336 \\
\hline \multicolumn{5}{|c|}{ Reduction rate (\%): preoperative to follow-up } \\
\hline Peak TVG (\%) & $72.0 \pm 12.6$ & $75.6 \pm 9.9$ & $67.3 \pm 15.9$ & 0.131 \\
\hline Mean TVG (\%) & $73.7 \pm 8.9$ & $76.4 \pm 13.1$ & $69.8 \pm 12.5$ & 0.152 \\
\hline LVMI (\%) & $39.4 \pm 20.9$ & $41.9 \pm 18.4$ & $35.8 \pm 19.8$ & 0.109 \\
\hline
\end{tabular}

TVG, transvalvular gradients; LVMI, left ventricular mass index; other abbreviations as in Tables 1 and 2. *Data were compared between the non-PPM versus the moderate PPM; ${ }^{\mathrm{a}} P<0.05$ for postoperative (at discharge) data versus preoperative data; ${ }^{\mathrm{b}} P<0.05$ for follow-up data versus preoperative data.

limited value. Also, differences in baseline characteristics and prevalence of moderate versus severe P-PtM in the patient population, as well as the diversity of the implanted prosthesis and surgical approaches are believed to contribute.

Previous studies have demonstrated that the influence of P-PtM on postoperative outcomes is an age-dependent phenomenon. As reported by Mohty et al. [12] and Moon et al. [20], moderate -to- severe P-PTM was detrimental to survival in young patients ( $<60$ or 70 years of age), but its impacts on older patients are negligible. These findings might be related to the fact that younger patients are generally more physically active and they indeed have greater cardiac output requirements in relation to body size. However, in our series, younger age ( $<65$ years $)$ was not identified as an independent risk factor of increased midterm mortality and valve-related complications in patients with moderate P-PtM. A possible explanation could be that the proportion of patients with bioprosthetic valve in previous studies was as high as 67\%-77.8\% $[12,13]$. As P-PtM is a significant risk factor for accelerated degeneration of bioprosthetic heart valves [21], and bioprosthesis in younger patients may expose to the progression of valvular degeneration for a longer period of time, it seems very likely that the impact of moderate P-PtM on postoperative outcomes is more pronounced in younger patients than in older ones. In addition, our insignificant result might be owing to the limited numbers of the subgroup populations.

Some could argue that the use of mechanical prostheses in AVR may potentially increase mortality and morbidity compared with the use of bioprosthesis, particularly due to anticoagulation-related complications [22]. However, in the present study, which employed strict control of PT-INR within a range of 1.5-2.0, only three patients experienced anticoagulation-related adverse events, accounting for a linearized rate of $0.2 \%$ per patient-year. These complication rates are comparable to other reports of patients who underwent bioprostheses implantation $[2,12,13,15]$. According to the American College of Chest Physicians guidelines [23], our anticoagulant level is lower but is proved efficient in Chinese patients with mechanical heart valve prostheses [24,25]. Similarly, investigators from other Asian countries have demonstrated low 
incidence of thrombosis and hemorrhage complications with low intensity anticoagulant strategy, suggesting that mechanical valves are not a risk factor for postoperative adverse events with good control of PT-INR levels $(1.8-2.2)[2,9]$.

\section{Study limitations}

This study was subject to the limitations inherent to a retrospective, nonrandomized comparison of clinical data, so it is likely that a selection bias or unidentified confounders might have influenced the results. In the present study, moderate P-PtM was determined by echocardiographic-measured EOAi. As suggested by other studies $[8,26]$, the utilization of the measured EOAi to define P-PtM may lead to an underestimation of the impact of P-PtM on survival. Hence, it is reasonable that no significant impact of P-PtM on postoperative mortality was observed in our series. Moreover, the measurement of LVMI in our study was performed by M-mode echocardiography, which is regarded less accurate than magnetic resonance imaging.

The improvement of a patient's physical capacity was not quantified in the present study (eg. the use of the SF-36 questionnaire), and the impact of the moderate PPtM on patients' quality of life is thereby questionable. Beyond the preoperative LVEF and age, body mass index is also an important factor that may have a significant impact on postoperative outcomes. However, in our series, only a small proportion of patients (11 patients) have a body mass index above $25 \mathrm{~kg} / \mathrm{m}^{2}$. Hence, the observed effects of the moderate P-PtM on midterm outcomes after AVR with a 17-mm Regent valve cannot be generalized to obese patients. In addition, the small number of patients with severe P-PtM in our series prevented our further investigation of the long-term safety and effectiveness of the 17-mm Regent valve.

\section{Conclusions}

Moderate P-PtM after implantation of a small mechanical prosthesis at aortic position is associated with increased midterm mortality and valve-related complications in patients with pre-existing LV dysfunction. Selected patients with small aortic annulus can experience satisfactory clinical results and midterm survival after isolated AVR with a 17-mm SJMR valve.

\footnotetext{
Abbreviations

AVR: Aortic valve replacement; BSA: Body surface area; EOA(i): Effective orifice area (index); LV: Left ventricle; LVM(i): Left ventricular mass (index); LVEF: Left ventricular ejection fraction; NYHA: New York Heart Association; PPtM: Prosthesis-patient mismatch; PT-INR: International normalized ratio of prothrombin time; SJMR: St. Jude Medical Regent.
}

\section{Competing interests}

The authors declare that they have no competing interests.

\section{Authors' contributions}

$\mathrm{JH}$ designed the protocol, analyzed data, contributed to the discussion and wrote the manuscript. HQ, YL and JG collected, researched data, contributed to the discussion. JJZ analyzed and researched data. EZ contributed to the discussion and reviewed/edited the manuscript. All authors read and approved the final manuscript.

\section{Acknowledgements}

This work was supported by the National Natural Science Foundation of China (No. 81300155 and No. 81370413). Special thanks to the support and kind assistance from Janice Zhao in reviewing the final submission.

\section{Author details}

${ }^{1}$ Department of Cardiovascular Surgery, West China Hospital, Sichuan University, Chengdu, People's Republic of China. ${ }^{2}$ Department of Cardiology, West China Hospital, Sichuan University, Chengdu, People's Republic of China.

Received: 1 October 2013 Accepted: 2 January 2014

Published: 17 January 2014

\section{References}

1. Mizoguchi H, Sakaki M, Inoue K, Iwata T, Tei K, Miura T: Mid-term results of small-sized St. Jude Medical Regent prosthetic valves (21 $\mathrm{mm}$ or less) for small aortic annulus. Heart Vessels. doi:10.1007/s00380-012-0306-X.

2. Okamura H, Yamaguchi A, Nagano H, Itoh S, Morita H, Naito K, Yuri K, Adachi $\mathrm{H}$ : Mid-term outcomes after aortic valve replacement with the 17-mm St. Jude Medical Regent valve. Circ J 2012, 76:365-371.

3. Coutinho GF, Correia PM, Paupério G, De Oliveira F, Antunes MJ: Aortic root enlargement does not increase the surgical risk and short-term patient outcome? Eur J Cardiothorac Surg 2011, 40:441-447.

4. Kulik A, Al-Saigh M, Chan V, Masters RG, Bédard P, Lam BK, Rubens FD, Hendry PJ, Mesana TG, Ruel M: Enlargement of the small aortic root during aortic valve replacement: is there a benefit? Ann Thorac Surg 2008, 85:94-100.

5. Bleiziffer S, Ali A, Hettich IM, Akdere D, Laubender RP, Ruzicka D, Boehm J, Lange $R$, Eichinger W: Impact of the indexed effective orifice area on mid-term cardiac-related mortality after aortic valve replacement. Heart 2010, 96:865-871.

6. Head SJ, Mokhles MM, Osnabrugge RL, Pibarot P, Mack MJ, Takkenberg JJ, Bogers AJ, Kappetein AP: The impact of prosthesis-patient mismatch on long-term survival after aortic valve replacement: a systematic review and meta-analysis of 34 observational studies comprising 27186 patients with 133141 patient-years. Eur Heart J 2012, 33:1518-1529.

7. Hong S, Yi G, Youn YN, Lee S, Yoo KJ, Chang BC: Effect of the prosthesis-patient mismatch on long-term clinical outcomes after isolated aortic valve replacement for aortic stenosis: a prospective observational study. J Thorac Cardiovasc Surg. doi:10.1016/j.ttcvs.2012.07.101.

8. Daneshvar SA, Rahimtoola SH: Valve prosthesis-patient mismatch (VP-PM): a long-term perspective. J Am Coll Cardiol 2012, 60:1123-1135.

9. Takaseya T, Kawara T, Tokunaga S, Kohno M, Oishi Y, Morita S: Aortic valve replacement with 17-mm St. Jude Medical prostheses for a small aortic root in elderly patients. Ann Thorac Surg 2007, 83:2050-2053.

10. Okamura H, Yamaguchi A, Tanaka M, Naito K, Kimura N, Kimura C, Kobinata T, Ino T, Adachi H: The 17-mm St. Jude Medical Regent valve is a valid option for patients with a small aortic annulus. Ann Thorac Surg 2009, 87:90-94.

11. Okamura H, Yamaguchi A, Noguchi K, Naito K, Yuri K, Adachi H: Hemodynamics and outcomes of aortic valve replacement with a 17- or 19-mm valve. Asian Cardiovasc Thorac Ann 2010, 18:450-455.

12. Mohty D, Dumesnil JG, Echahidi N, Mathieu P, Dagenais F, Voisine P, Pibarot P: Impact of prosthesis-patient mismatch on long-term survival after aortic valve replacement: influence of age, obesity, and left ventricular dysfunction. J Am Coll Cardio/ 2009, 53:39-47.

13. Jamieson WR, Ye J, Higgins J, Cheung A, Fradet GJ, Skarsgard P, Germann E, Chan F, Lichtenstein SV: Effect of prosthesis-patient mismatch on long-term survival with aortic valve replacement: assessment to 15 years. Ann Thorac Surg 2010, 89:51-58.

14. Mannacio V, Di Tommaso L, Stassano P, De Amicis V, Vosa C: Myocardial metabolism and diastolic function after aortic valve replacement for aortic stenosis: influence of patient-prosthesis mismatch. Eur J Cardiothorac Surg 2012, 41:316-321.

15. Mohty D, Malouf JF, Girard SE, Schaff HV, Grill DE, Enriquez-Sarano ME, Miller FA Jr: Impact of prosthesis-patient mismatch on long-term survival 
in patients with small St Jude Medical mechanical prostheses in the aortic position. Circulation 2006, 113:420-426.

16. Lang RM, Bierig M, Devereux RB, Flachskampf FA, Foster E, Pellikka PA, Picard MH, Roman MJ, Seward J, Shanewise JS, Solomon SD, Spencer KT, Sutton MS, Stewart WJ: Chamber Quantification Writing Group; American Society of Echocardiography's Guidelines and Standards Committee; European Association of Echocardiography. Recommendations for chamber quantification: a report from the American Society of Echocardiography's Guidelines and Standards Committee and the Chamber Quantification Writing Group, developed in conjunction with the European Association of Echocardiography, a branch of the European Society of Cardiology. J Am Soc Echocardiogr 2005, 18:1440-1463.

17. Akins CW, Miller DC, Turina Ml, Kouchoukos NT, Blackstone EH, Grunkemeier GL, Takkenberg JJ, David TE, Butchart EG, Adams DH, Shahian DM, Hagl S, Mayer JE, Lytle BW: STS; AATS; EACTS. Guidelines for reporting mortality and morbidity after cardiac valve interventions. Ann Thorac Surg 2008, 85:1490-1495.

18. Minardi G, Manzara C, Creazzo V, Maselli D, Casali G, Pulignano G, Musumeci F: Evaluation of 17-mm St. Jude Medical Regent prosthetic aortic heart valves by rest and dobutamine stress echocardiography. J Cardiothorac Surg 2006, 1:27.

19. Amarelli C, Della Corte A, Romano G, lasevoli G, Dialetto G, De Santo LS, De Feo M, Torella M, Scardone M, Cotrufo M: Left ventricular mass regression after aortic valve replacement with $17-\mathrm{mm}$ St Jude Medical mechanical prostheses in isolated aortic stenosis. J Thorac Cardiovasc Surg 2005, 129:512-517.

20. Garatti A, Mori F, Innocente F, Canziani A, Gagliardotto P, Mossuto E, Santoro T, Montericcio V, Frigiola A, Menicanti L: Aortic valve replacement with 17-mm mechanical prostheses: is patient-prosthesis mismatch a relevant phenomenon? Ann Thorac Surg 2011, 91:71-77.

21. Flameng $W$, Herregods MC, Vercalsteren $M$, Herijgers $P$, Bogaerts $K$, Meuris $B$ : Prosthesis-patient mismatch predicts structural valve degeneration in bioprosthetic heart valves. Circulation 2010, 121:2123-2129.

22. Brennan JM, Edwards FH, Zhao Y, O'Brien S, Booth ME, Dokholyan RS, Douglas PS, Peterson ED: DEcIDE AVR (Developing Evidence to Inform Decisions about Effectiveness-Aortic Valve Replacement) Research Team. Long-term safety and effectiveness of mechanical versus biologic aortic valve prostheses in older patients: results from the Society of Thoracic Surgeons Adult Cardiac Surgery National Database. Circulation 2013, 127(16):1647-1655.

23. Whitlock RP, Sun JC, Fremes SE, Rubens FD, Teoh KH: American College of Chest Physicians. Antithrombotic and thrombolytic therapy for valvular disease: Antithrombotic Therapy and Prevention of Thrombosis, 9th ed: American College of Chest Physicians Evidence-Based Clinical Practice Guidelines. Chest 2012, 141(2 Suppl):e576S-600S.

24. Han QQ, Xu ZY, Zhang BR, Zou LJ, Hao JH, Huang SD: Primary triple valve surgery for advanced rheumatic heart disease in Mainland China: a single-center experience with 871 clinical cases. Eur J Cardiothorac Surg 2007, 31:845-850.

25. Fu B, Chen H, Dong L: Antithrombotic and thrombolytic therapy for valvular disease: can this guideline apply to Chinese? Chest 2013, 143(5):1513-1514.

26. Pibarot P, Dumesnil JG: Valve prosthesis-patient mismatch, 1978 to 2011 : from original concept to compelling evidence. J Am Coll Cardiol 2012, 60:1136-1139.

\section{doi:10.1186/1749-8090-9-17}

Cite this article as: Hu et al:: Seventeen-millimeter St. Jude Medical Regent valve in patients with small aortic annulus: dose moderate prosthesis-patient mismatch matter?. Journal of Cardiothoracic Surgery 2014 9:17.

\section{Submit your next manuscript to BioMed Central and take full advantage of:}

- Convenient online submission

- Thorough peer review

- No space constraints or color figure charges

- Immediate publication on acceptance

- Inclusion in PubMed, CAS, Scopus and Google Scholar

- Research which is freely available for redistribution 